\title{
Intestinal thromboangiitis obliterans in a woman: A case report and discussion of chronic ischemic changes
}

\author{
Shaun AC Medlicott MD ${ }^{1}$, Paul Beaudry MD², Gary Morris $M D^{3}$, Gwen Hollaar MD², Francis Sutherland $M D^{2}$
}

\begin{abstract}
SAC Medlicott, P Beaudry, G Morris, G Hollaar, F Sutherland. Intestinal thromboangiitis obliterans in a woman: A case report and discussion of chronic ischemic changes. Can J Gastroenterol 2003;17(9):559-561.

Although traditionally regarded as a disease of distal extremities, mesenteric vasculature can also manifest thromboangiitis obliterans (TAO). There are 31 cases of intestinal TAO in the English literature and the majority of subjects are male. However, cases of women with $\mathrm{TAO}$ are becoming more common, coinciding with an increased incidence of smoking in this sex. We describe the sixth case of a female patient with classic extremity manifestations paralleled by paroxysms of abdominal angina. Intestinal TAO can mimic extremity disease of smoldering chronic ischemia punctuated by unpredictable acute episodes of gangrene. In the present case, chronic ischemia manifested as partial bowel obstruction due to stricture deformity of the ileum and profound adipocyte atrophy of mesentery.
\end{abstract}

Key Words: Buerger's disease; Female; Intestine; Lipid atrophy

\section{Une thromboangéite oblitérante intestinale chez une femme : Rapport de cas et discussion des modifications ischémiques}

\section{CASE PRESENTATION}

The patient was an otherwise healthy 43-year-old woman with a 30-pack-year history of smoking and Raynaud's disease. Of note, she had no heart disease, hypertension, thrombophilia, repetitive pregnancy loss, connective tissue disorder or malignancy. She was prescribed a vasodilator (nifedipine $30 \mathrm{mg}$ daily) for Raynaud's disease.

She complained of postprandial stomach cramps for four years, that intensified over the last 12 months, prompting multiple emergency room visits. The pain was vague and not associated with changes in bowel habit or stool appearance; she had lost $14 \mathrm{~kg}$ over the last year. Endoscopy examination was unremarkable. She was diagnosed with intestinal angina but continued to smoke against medical advice.

Three months before her most recent admission, she developed acute intractable pain of her left hand third digit. Angiograms of the aorta and extremities identified segmental occlusions of the splenic artery, midarm brachial arteries, radial artery of the right wrist, numerous digital arteries and tibial arteries. Larger vessels reconstituted distal to the occlusions via tortuous collaterals. Her left hand third digit began to ulcerate and an amputation was performed. Histological examination was negative for vasculitis.
Two months before her most recent admission, she developed escalating right leg claudication. Serology showed a negative or normal antinuclear antibody, antineutrophil cytoplasmic antibodies (myeloperoxidase and proteinase-3), anticardiolipin, anti-DNA antibody, rheumatoid factor, homocysteine, hepatitis B and hepatitis C status. \{Please confirm\} A diagnosis of Buerger's disease was not established definitively due to splenic artery occlusion. Her painful and progressively ischemic right leg was recalcitrant to a course of cyclophosphamide and steroids.

Intractable right leg pain and abdominal angina prompted her most recent hospital admission. The initial abdominal radiographs revealed a marked distension of the stomach and loops of bowel, consistent with small bowel obstruction. Leg claudication was accompanied by absent popliteal and pedal pulses via Doppler ultrasound. An above-knee amputation was performed. Once again, histological examination of the limb was negative for vasculitis (Figure 1).

Two weeks later, she developed an acute abdomen with free air under the diaphragm identified radiographically. Exploration at laparotomy confirmed a stricture of the distal ileum, compatible with chronic ischemia. The distal jejunum was gangrenous. Two segmental resections of bowel with pri-

${ }^{1}$ Calgary Laboratory Services, ${ }^{2}$ Department of General Surgery, ${ }^{3}$ Department of Internal Medicine, Peter Lougheed Hospital, University of Calgary, Calgary, Alberta

Correspondence and reprints: Dr S Medlicott, Calgary Laboratory Services, Peter Lougheed Hospital, 350026 Street North East, Calgary, Alberta

T1Y 6J4. Telephone 403-943-4907, fax 403-291-2931, e-mail shaun.medlicott@cls.ab.ca

Received for publication May 26, 2003. Accepted June 10, 2003 




Figure 1) Serial sections of the right popliteal artery delineate concentric segmental occlusion due to an acute thrombus (inset, hematoxylin and eosin, original magnification $\times 100$ )

mary anastomoses were performed. She developed multisystem organ failure and died 35 days after admission.

Histomorphology of the extremity and the viscera vasculature was identical. No atherosclerosis, leukocytoclasis or fibrinoid necrosis was seen. The disease was almost exclusively confined to small and medium-sized arteries. On examination, the predominant vessel alteration was noted to be segmental thrombi of varying ages. Recent thrombi were associated with a mild lymphocytic and neutrophil transmural infiltrate but no giant cells, fibrous scarring or interruption of elastic lamina. Prominence of endothelial cells was obvious. Subacute thrombi had intraluminal pigment-laden macrophages and fibrin with an enmeshing of fibroblasts. These vessels had the most florid lamellar hypertrophy of internal elastic lamina. Small endothelialized channels recanalized chronic thrombi. The media of such vessels were intact.

Adipose tissue of the subcutis, mesentery and subserosa had localized lipoatrophy. Atrophy of adipocytes was mild in the finger and leg but profound in the mesenteric tissue (Figure 2). Presumably, both chronic ischemia and anorexia contributed to this atrophy.

\section{DISCUSSION}

Thromboangiitis obliterans (TAO) is an obliterative inflammatory disease of small arteries and veins. Young adult males who smoke heavily are at risk. However, women with TAO are becoming more common, coinciding with an increased incidence of smoking in this sex (1). As such, the disease may be a toxic angiitis or delayed hypersensitivity to vessel wall collagens I and III (2). A genetic predisposition is suggested (human leukocyte antigen-A9 or B5) and concurrent hyperhomocysteinemia may predict a poor prognosis $(3,4)$.

The diagnosis of TAO necessitates the exclusion of vasculitides, atherosclerosis, thrombophilias, dysrrhythmias and drug (ergot) ingestion. Specific diagnostic criteria, proven by longterm follow up, are all of a smoking history, disease onset before the age of 50 years, infrapopliteal arterial occlusions, either upper limb involvement or phlebitis migrans and absence of

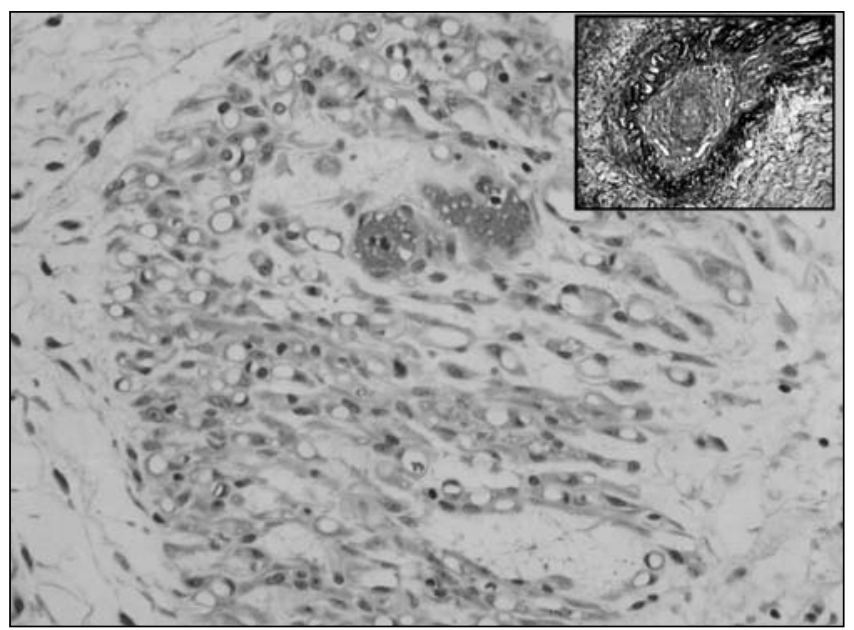

Figure 2) Localized lipoatrophy of small bowel mesentery; typical lobular distribution of adipocytes about vessels is maintained (hematoxylin and eosin, original magnification $\times 400)$. A subacute thrombus and elastic lamina lamellar hypertrophy is noted in an adjacent mesenteric artery (inset, elastic van Gieson, original magnification $\times 250$ )

other atherosclerosis risk factors (5). Our patient satisfies these criteria. Her serology and angiograms were also indicative of TAO. Splenic artery occlusion was initially difficult to reconcile with our diagnosis; however, rare case reports verify splenic artery involvement in TAO $(6,7)$. Thus, when histological examination proved negative for vasculitis, the diagnosis of Buerger's disease was confirmed.

Although traditionally regarded as a disease of distal extremities, Buerger indicated that mesenteric vasculature could manifest TAO (8). Intestinal TAO is an established entity with 31 cases described in the English literature. Approximately $50 \%$ of published cases indicate that Buerger's disease was verified by angiogram (9). Remaining subjects required a histological assessment of their necrotic bowel resections, as was the case presently. Intestinal TAO is a segmental process that preferentially afflicts the small bowel (70\%) (7). Acute gangrenous episodes are ominous, with a $30 \%$ mortality rate $(10)$. However, chronic ischemia may be managed successfully via bypass surgery $(7,11,12)$.

Chronic ischemia of intestinal TAO appears to manifest as partial bowel obstruction (13). Symptomatology is usually nonspecific cramps or abdominal angina that contributes to significant weight loss $(7,14)$. More specifically, postprandial cramping and pain, as noted in our patient, has been identified in four other cases $(7,11,12,15)$. The morphology of segmental bowel disease includes occasional stricture formation, with or without confounding acute necrosis (14-17).

Anorexia, but also chronic arterial obstruction, classically causes localized lipoatrophy of the subcutis and omentum (18). In a series of 29 limbs amputated for end-stage TAO, 11 (38\%) demonstrated membranocystic changes (19). Mild lipoatrophy was evident in the subcutis of our patient's extremities. In contrast, bowel subserosa and mesentery had profound atrophy. Variable arterial obstruction and degree of chronic ischemia probably contributed to such a heterogeneous pattern of atrophy (as presumably, confounding anorexia may facilitate a consistent distribution). More studies are warranted to verify our finding and characterize visceral lipoatrophy in Buerger's disease. 


\section{CONCLUSIONS}

Cases of women with TAO are becoming more prevalent, including subjects with intestinal involvement. Our case demonstrates the chronic ischemic and acute gangrenous elements of intestinal TAO. Chronic ischemia manifested as partial bowel obstruction due to stricture deformity of the ileum. Postprandial cramping was experienced years before the acute gangrenous event. A novel finding presently is profound mesenteric lipoatrophy. Atrophy of visceral adipose tissue should be expected, as it is a well-documented feature of extremity TAO.

\section{REFERENCES}

1. Yorukoglu Y, Ilgit E, Zengin M, Nazliel K, Salman E, Yucel E. Thromboangiitis obliterans (Buerger's disease) in women (a reevaluation). Angiology 1993;44:527-32.

2. Adar R, Papa MZ, Halpern Z, et al. Cellular sensitivity to collagen in thromboangitis obliterans. N Eng J Med 1983;308:1113-6.

3. McLoughin GA, Helsby CR, Evans CC, Chapman DM. Association of HLA-9 and HLA-B5 with Buerger's disease. Br J Med 1976;2:1165-6.

4. Diehm C, Stammlet F. Thromboangiitis obliterans (Buerger's disease). N Engl J Med 2001;344:230.

5. Shionoya S. Diagnostic criteria of Buerger's disease. Int J Cardiol 1998;66(Suppl 1):S243-5.

6. Korsgaard N, Johansen A, Baandrup U. A case of thromboangiitis obliterans affecting coronary, pulmonary, and splenic vessels. Is thromboangitis obliterans a generalized vascular disease? Am J Cardiovasc Path 1988;2:263-7.

7. Iwai T. Buerger's disease with intestinal involvement. Int J Cardiol 1998;66(Suppl 1):S257-63.
8. Buerger L. The Circulatory Disturbance of the Extremities Including Gangrene, Vasomotor and Trophic Disorders. Philadelphia: Saunders, 1924.

9. Sauvaget F, Debray M, De Sigalony JP, et al. Colonic ischemia reveals thromboangiitis obliterans (Buerger's disease). Gastroenterology 1996;110:900-3.

10. Lie JT. Visceral intestinal Buerger's disease. Int J Cardiol 1998;(Suppl 1):S249-56.

11. Schellong SM, Bernhards J, Ensslen F, Schafers HJ, Alexander K. Intestinal type of thromboangiitis obliterans (Buerger's) disease. J Int Med 1994;235:69-73.

12. Kempczinski RF, Clark SM, Blebea J, Koelliker DD, Fenoglio-Preiser C. Intestinal ischemia secondary to thromboangiitis obliterans. Ann Vasc Surg 1993;7:354-8.

13. Rob C. Sugical diseases of the celiac and mesenteric arteries. Arch Surg 1966;93:21-32.

14. Rosen N, Sommer I, Knobel B. Intestinal Buerger's disease. Arch Pathol Lab Med 1985;109:962-3.

15. Hassoun Z, Lacrosse M, De Ronde T. Intestinal involvement in Buerger's disease. J Clin Gastroenterol 2001;32:85-9.

16. Herrington JL, Grossman LA. Surgical lesions of the small and large intestine resulting from Buerger's disease. Ann Surg 1968;68:1079-87.

17. Arkkila PET, Kahri A, Farkkila M. Intestinal type of thromboangiitis obliterans (Buerger disease) preceding symptoms of severe peripheral arterial disease. Scand J Gastroenterol 2001;6:669-72.

18. Brooks JJ, Perosio PM. Adipose tissue. In: Sternberg SS, ed. Histology for Pathologists. New York: Raven, 1992:43-44.

19. Machinami R. Incidence of membranous lipodystrophylike change among patients with limb necrosis caused by chronic arterial obstruction. Arch Pathol Lab Med 1984;108:823-6. 


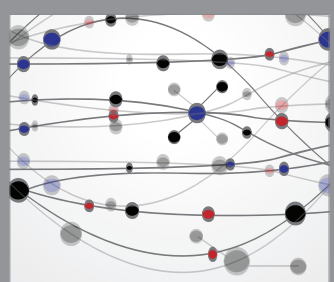

The Scientific World Journal
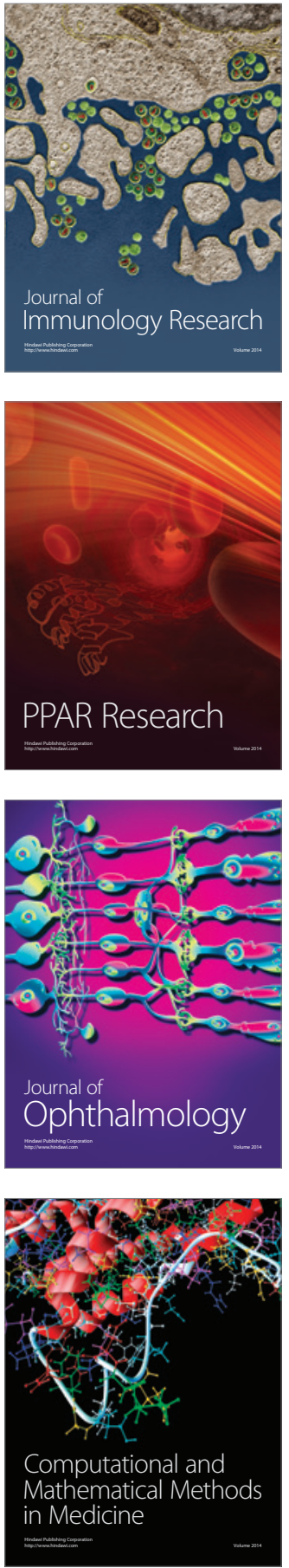

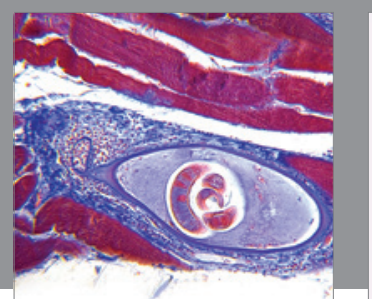

Gastroenterology Research and Practice

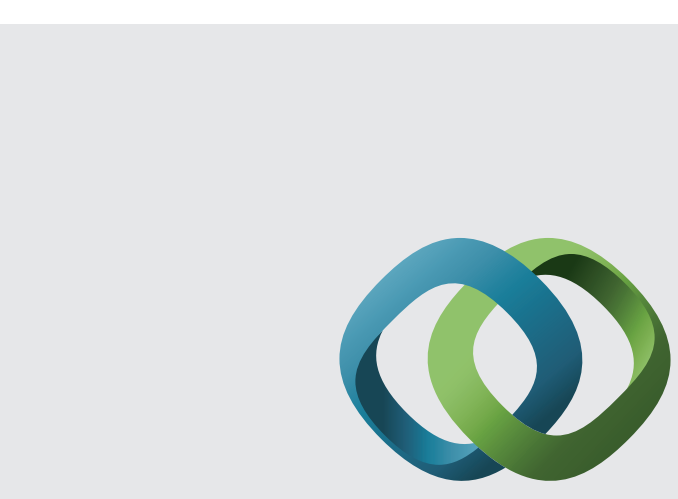

\section{Hindawi}

Submit your manuscripts at

http://www.hindawi.com
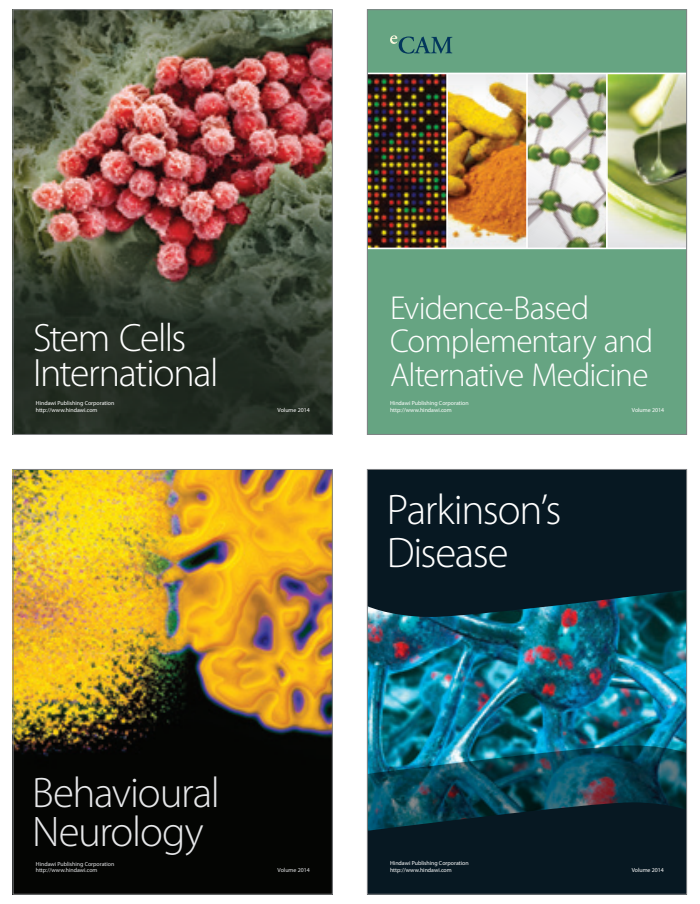
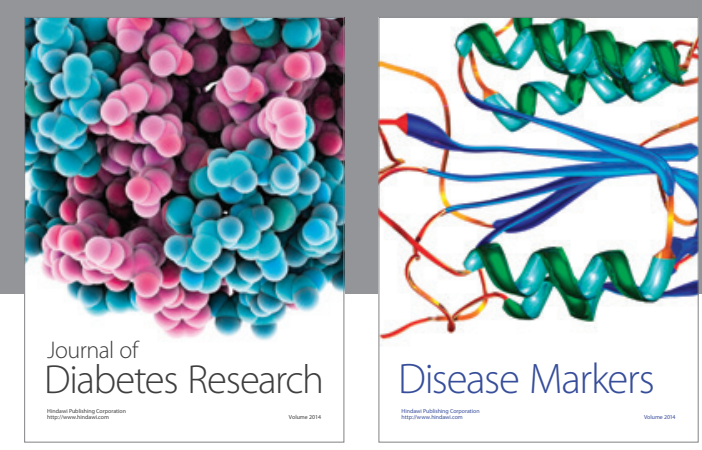

Disease Markers
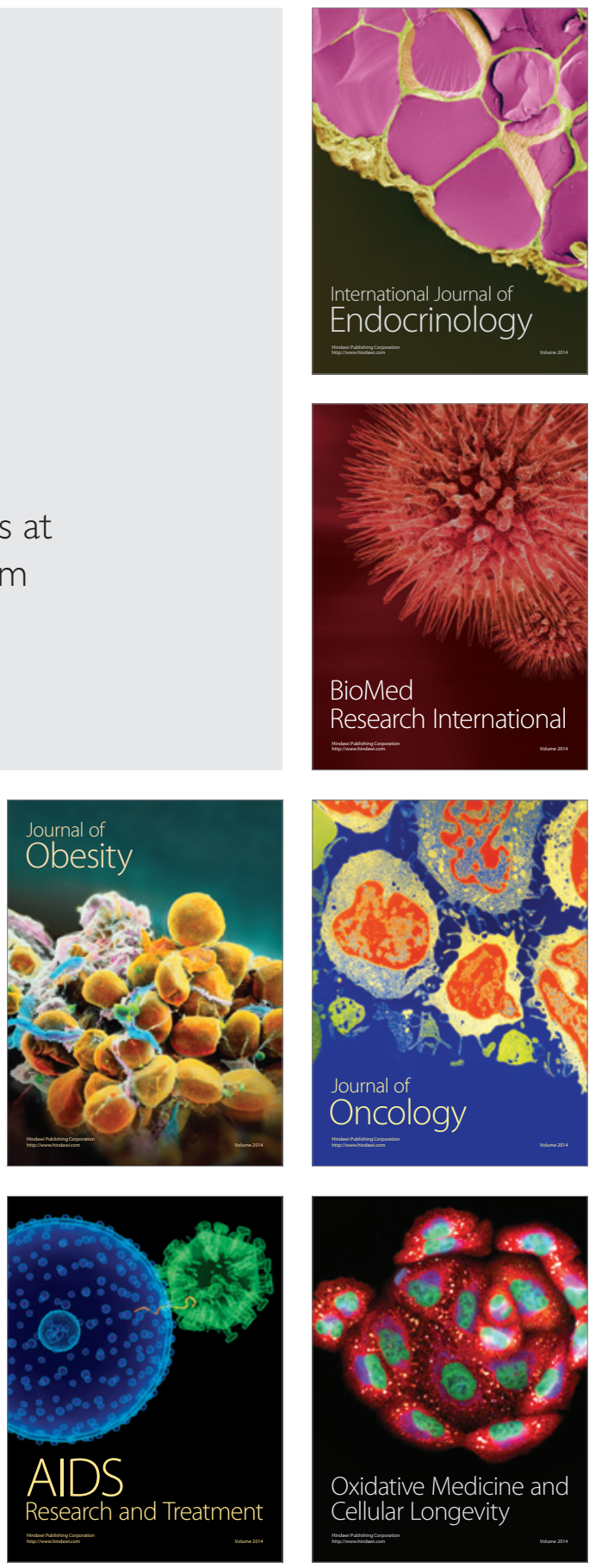